\title{
Effects of Intermittent Parathyroid Hormone Treatment on Osteoprogenitor Cells in Postmenopausal Women
}

\author{
Matthew T. Drake*, Bhuma Srinivasan*, Ulrike I. Mödder, Alvin C. Ng, Anita H. Undale, \\ Matthew M. Roforth, James M. Peterson, Louise K. McCready, B. Lawrence Riggs, and \\ Sundeep Khosla \\ Endocrine Research Unit, College of Medicine, Mayo Clinic, Rochester, MN, USA.
}

\begin{abstract}
Intermittent parathyroid hormone (PTH) 1-34 treatment stimulates bone formation, but the molecular mechanisms mediating this effect have not been previously studied in humans. Thus, we used magnetic activated cell sorting to isolate hematopoietic lineage negative (lin-)/alkaline phosphatase positive (AP+) osteoprogenitor cells from bone marrow of 20 postmenopausal women treated with PTH (1-34) for 14 days and 19 control subjects. Serum PINP and CTX increased in PTH-treated subjects (by $97 \%$ and $30 \%$, respectively, $\mathrm{P}<0.001$ ). Bone marrow lin-/ $\mathrm{AP}+$ cells from $\mathrm{PTH}$-treated subjects showed an increase in the RANKL/OPG mRNA ratio (by 7.5-fold, $\mathrm{P}=0.011$ ) and in the mRNAs for $\mathrm{c}$-fos (a known PTH-responsive gene, by $42 \%, \mathrm{P}=$ 0.035 ) and VEGF-C (by 57\%, P = 0.046). Gene Set Enrichment Analysis (GSEA, testing for changes in pre-specified pathways) demonstrated that PTH had no effect on osteoblast proliferation, apoptosis, or differentiation markers. However, PTH treatment resulted in a significant decrease (GSEA P-value, 0.005) in a panel of BMP target genes in the lin-/AP+ cells. Our findings thus identify several future directions for studying mechanisms of PTH action in humans. First, given the increasing evidence that PTH induces angiogenesis, the role of increased VEGF-C production by bone marrow osteoprogenitor cells in mediating this effect and the anabolic response to PTH warrants further study. Second, while the observed inhibition of BMP target gene expression by PTH is not consistent with the anabolic effects of PTH on bone and requires further validation, these data do generate the hypothesis that an inhibition of BMP signaling by PTH may, over time, limit the availability of mature osteoblasts on bone surfaces and thereby contribute to the observed waning of the anabolic response to PTH.
\end{abstract}

\section{Keywords}

postmenopausal women; PTH; anabolic; osteoporosis

\section{INTRODUCTION}

Among the medical therapies in the United States approved for the treatment of osteoporosis, only parathyroid hormone (PTH) 1-34 given as a daily subcutaneous injection

() 2011 Elsevier Inc. All rights reserved.

Corresponding author: Sundeep Khosla, M.D., Endocrine Research Unit, Guggenheim 7-11, Mayo Clinic, 200 First Street SW, Rochester, MN 55905. Phone: (507) 255-6663, Fax: (507) 293-3853, khosla.sundeep@ mayo.edu.

Both authors contributed equally to this work

Publisher's Disclaimer: This is a PDF file of an unedited manuscript that has been accepted for publication. As a service to our customers we are providing this early version of the manuscript. The manuscript will undergo copyediting, typesetting, and review of the resulting proof before it is published in its final citable form. Please note that during the production process errors may be discovered which could affect the content, and all legal disclaimers that apply to the journal pertain. 
functions as an anabolic agent to promote bone accrual [1]. When used pharmacologically, daily injection of PTH 1-34 induces the formation of trabecular, endocortical, and periosteal bone $[2,3]$. In turn, these changes in skeletal microarchitecture provide a structural basis for the reduction in vertebral and non-vertebral fracture incidence seen with PTH 1-34 treatment [1].

Despite the well-established biologic activity of intermittent PTH 1-34 treatment, the molecular mechanisms mediating this effect have not been previously studied in humans. Part of the difficulty in unequivocally defining the mechanism(s) for the anabolic effects of PTH is that these effects likely involve multiple cell types and pathways. Thus, PTH might modulate the function of osteoprogenitor cells, mature osteoblasts, bone-lining cells, osteocytes, and/or osteoclasts to ultimately stimulate bone formation [4]. Biochemically, the increase in bone formation following PTH 1-34 therapy is associated with increases in circulating markers of osteoblast function, including alkaline phosphatase (AP), osteocalcin, and amino terminal propeptide of type I collagen (PINP).

To date, efforts to understand the molecular basis for the anabolic effects of PTH 1-34 have used either rodent models or in vitro culture systems. As described by Partridge and colleagues in work with femoral metaphyseal trabecular specimens from rats exposed to intermittent PTH 1-34, the expression of multiple genes encoding signaling mediators, transcription factors, cytokines, and proteases/protease inhibitors are differentially regulated in response to PTH 1-34 treatment [5]. Similarly, in vitro studies of osteoblast-like cell lines [6] or primary murine cultured marrow cells [7] have demonstrated that intermittent PTH 134 treatment results in changes in the expression of distinct sets of genes than when PTH 134 is used continuously. However, in vitro culture model systems are unlikely to accurately reflect the complex cellular milieu within human bone. Accordingly, our understanding of the molecular basis for the effects of intermittent PTH 1-34 therapy in humans, and in particular the effect of PTH 1-34 on osteoblasts or their progenitors, remains limited.

In order to overcome these obstacles, we have developed methods for the isolation of osteoprogenitor cells directly from human bone marrow aspirates [8-10]. Osteoblasts are derived from multipotential mesenchymal stem cells (MSC's) within the bone marrow, and a number of potential markers for the identification of MSCs have been developed in recent years [11]. While AP is expressed by mature osteoblasts, recent studies have demonstrated that the $\mathrm{AP}+$ fraction of human bone marrow contains virtually all of the osteoprogenitor population in the marrow [12], indicating that AP expression is associated not only with mature osteoblasts, but likely also with osteoblastic cells at varying stages of differentiation, including relatively early mesenchymal cells. Thus, we isolated hematopoietic lineage negative (lin-)/AP+ cells from the bone marrow of control versus PTH-treated postmenopausal women and performed gene expression analysis to determine differences induced in response to PTH treatment.

\section{METHODS}

\section{Study subjects}

Fifty-five untreated postmenopausal women between the ages of 55 and 85 years were randomized into an open label, controlled study to receive once daily PTH $1-34(\mathrm{n}=27)$ treatment or no treatment $(n=28)$ for 14 days. From the initial group of 55 postmenopausal women included in the study, 20 subjects who received PTH 1-34 and 19 subjects who did not receive treatment were randomly selected and agreed to bone marrow aspiration. Effects of PTH on serum sclerostin, OPG, and other biomarker levels in the larger cohort of 55 subjects have been reported separately, where we also provide details regarding the inclusion and exclusion criteria used as well as the measures undertaken in order to ensure 
vitamin D sufficiency prior to study [13]. All subjects provided written informed consent, and the study was approved by the Mayo Clinic Institutional Review Board.

\section{Experimental protocol}

Subjects were randomly assigned to receive either once-daily PTH (1-34) at a dose of 40 $\mu \mathrm{g}$, or no treatment. The PTH (1-34) used was as sold by Eli Lilly under the brand name Forteo. The $40 \mu \mathrm{g} / \mathrm{d}$ dose was chosen so as to ensure the most robust changes in gene expression and since this was one of the two doses used in the original clinical trials [1]. To minimize the risk of hypercalcemia or hypercalciuria, all subjects in our study were maintained on a diet containing $600 \mathrm{mg} / \mathrm{d}$ calcium for the 15 days of the study.

All subjects had serum studies performed on the two consecutive days prior to beginning treatment and again on the $13^{\text {th }}$ and $14^{\text {th }}$ days of treatment. Fasting morning serum samples were obtained for measurement of serum calcium, phosphorus, creatinine, P1NP, osteocalcin, carboxy-terminal cross-linking telopeptides of type I collagen (CTX), and isoform $5 \mathrm{~b}$ of tartrate resistant acid phosphatase (TRAP5b). Serum samples were stored at $-70^{\circ} \mathrm{C}$ in the laboratory until analysis.

\section{Isolation of lin-/AP+ cells}

Bone marrow aspiration $(30 \mathrm{ml})$ was performed at $8 \mathrm{AM}$ on the morning of the $15^{\text {th }}$ day, 4 hours following adminstration of the final PTH dose in the subjects randomized to PTH treatment and at the same $8 \mathrm{AM}$ time point in control subjects. The decision to obtain the bone marrow aspirate (and final blood draw) at a time point 4 hours following PTH 1-34 adminstration was made in order to maximize our ability to detect changes in gene expression following PTH treatment, since previous studies in rodents have demonstrated that early time points following PTH treatment may show more dramatic changes than 24 hours following PTH dosing [5, 14].

Bone marrow cells were initially subjected to Ficoll gradient centrifugation for mononuclear (MNC) cell enrichment. After incubation of the MNC fraction with a StemSep Human Progenitor enrichment cocktail (StemCell Technologies) containing antibodies to CD2, CD3, CD14, CD16, CD19, CD24, CD56, CD66b and glycophorin A, depletion of hematopoietic cells was accomplished by passage over a magnetic column; this essentially removed T cells, B cells, neutrophils and erythroid cells. Subsequent enrichment for lin-/AP + cells was performed by magnetic activated cell sorting (MACS) using a biotinylated AP antibody ( $\mathrm{R} \& \mathrm{D}$ systems) followed by staining with antibiotin beads (Miltenyi Biotec). The yield of lin-/AP+ cells was 95,000 $\pm 17,000$ (range, 31,000-340,000) in the control group and 93,000 $\pm 19,000$ (range, 4000-280,000) in the PTH group. We have previously shown that these bone marrow lin-/AP+ cells are largely CD45- (only $12.5 \%$ express CD 45 by flow cytometry) [10]. Isolated cells were stored at $-70^{\circ} \mathrm{C}$ in RLT buffer until further analysis.

\section{Gene expression studies}

Total RNA from the bone marrow-derived lin-/AP+ cell population was isolated using microfuge columns (Microcolumns, Qiagen). DNase treatment to digest all genomic DNA that could lead to false positive gene expression results was done following RNA isolation using Turbo DNA-free DNase (Ambion). RNA quality and purity was confirmed with a Nanodrop spectrophotometer (Thermo Scientific) and RNA integrity determined using the Agilent 2100 Bioanalyzer. Because the overall number of the lin-/AP+ cells was low and therefore the yield of total RNA was limited to run in-depth gene expression analyses, we used the WT-Ovation ${ }^{\mathrm{TM}}$ Pico RNA amplification system (NuGEN Technologies, Inc) to synthesize $\mu \mathrm{g}$ quantities of amplified cDNA starting with total RNA input amounts of $\sim 60$ 
ng. In this linear amplification system, the relative representation of each transcript species in the original sample is maintained during and after amplification $[15,16]$.

For the QPCR analyses, we designed primers using the Primer Express program (Applied Biosystems). Primer sequences for any of the genes analyzed in this report are available on request. The primers (1.8 pmol/reaction, MWG-Biotech AG, Ebersberg, Germany) were applied to 384-well PCR-plates in a sucrose solution (30\% sucrose, $1 \mathrm{mM}$ Tris $\mathrm{pH} 8.5$ ) and dried onto the plates for 1 hour in a heated speed vacuum. PCR reactions were then run in the ABI Prism 7900HT Real time System (Applied Biosystems) using SYBR Green (BioRad) as the detection method. $5 \mathrm{ng}$ of the amplified cDNA was used per reaction and each gene was run in triplicate in a total volume of $10 \mu 1$. Negative Reverse Transcriptase controls were included to check for genomic DNA contamination.

Normalization for variations in input RNA was performed using a panel of 10 housekeeping genes (18S, G6PDH, GAPDH, HPRT, L13a, RPII, TBP, $\alpha$-tubulin, $\beta 2$-microglobulin, $\beta$ actin) with the geNorm algorithm $[17,18]$ used to select the $3-4$ most stable housekeeping genes from the 10 on the plate. The PCR Miner algorithm [19] was used to correct for variations in amplification efficiencies, and the expression level in each subject for a given gene was normalized to the median expression level of that gene in the control subjects. QPCR arrays included genes for multiple pre-specified pathways: osteoblast differentiation, proliferation, apoptosis, bone morphogenetic protein (BMP) signaling, and Wnt signaling.

\section{Biochemical bone marker measurement}

For assessing bone formation, serum P1NP was measured by radioimmunoassay (Immunodiagnostic Systems; interassay CV, 9\%), and osteocalcin was measured using a two-site immunoradiometric assay (CIS-US; interassay CV, 8\%). For assessing bone resorption, serum CTX and TRAP5b were measured by ELISA (Immunodiagnostic Systems; interassay CV $<10 \%$ and $4 \%$, respectively).

\section{Statistical analyses}

The bone turnover marker data are presented as mean \pm SEM and comparisons between groups were done using 2-sample t-tests. However, since much of the gene expression data was not normally distributed, these data are presented as medians and interquartile $\left(25^{\text {th }}\right.$ $75^{\text {th }}$ percentile) ranges (IQR), and pairwise comparisons between the control and PTH treated groups were done using the Wilcoxon Rank Sum test. We used Gene Set Enrichment Analysis [20,21] to assess if changes in gene expression occurred along a priori defined pathways (osteoblast differentiation, proliferation and apoptosis markers, BMP target genes, and Wnt target genes), based on knowledge of cellular signaling. This method provides a more robust means to analyze gene expression data and increases the power of detecting changes in genes occurring in pre-specified clusters, rather than in isolation. $\mathrm{P}<0.05$ was considered significant.

\section{RESULTS}

\section{Characteristics of study subjects}

Table 1 shows the baseline anthropometric and biochemical variables in the study subjects. As is evident, the subjects were well matched with respect to age, height, weight, body mass index, and baseline biochemical parameters. All had 25-hydroxyvitamin D levels above 30 $\mathrm{ng} / \mathrm{dl}$, with no difference between the two groups. 


\section{Changes in bone turnover markers}

Figure 1 shows changes in the bone turnover markers in the two groups. As expected, serum PINP and osteocalcin levels increased significantly (by $97 \%$ and 50\%, respectively) in the PTH group; both markers decreased slightly (by $8 \%$ and 5\%, respectively) in the control group. Two weeks of PTH treatment at a dose of $40 \mu \mathrm{g} / \mathrm{d}$ did result in an increase in serum CTX and TRAP5b levels (of $30 \%$ and $8 \%$, respectively), but neither resorption marker changed in the control group.

\section{PTH-induced changes in known PTH target genes}

Since previous studies have found that intermittent PTH increases RANKL [22], decreases OPG [22], and increases c-fos [5] mRNA levels, we first tested whether the bone marrow lin -/AP+ cells were a PTH-responsive cell population by examining changes in mRNA levels for these genes. Compared to control subjects (median [IQR], $1.00[0.09,13.6]$ ), RANKL mRNA levels were increased $(7.27$ [3.00, 12.2], $\mathrm{P}=0.238)$ and OPG mRNA levels were reduced (control, 1.00 [0.50, 1.62]; PTH, 0.41 [0.42, 1.41], $\mathrm{P}=0.116$ ), resulting in a significant increase in the RANKL/OPG ratio in the PTH-treated subjects (control, 1.00 $[0.04,4.60]$; PTH 7.49 [2.07, 58.4], $\mathrm{P}=0.011$ ). Similarly, c-fos mRNA levels were higher in the PTH $(1.42[1.00,2.02])$ as compared to the control subjects $(1.00[0.73,1.36], \mathrm{P}=$ 0.035). Since the changes in RANKL and OPG were not significant when analyzed separately, and the changes in c-fos mRNA were modest, we also examined PTH receptor 1 mRNA levels in lin-/AP+ cells. While similar in control $(1.00[0.27,3.11)$ and PTH-treated subjects $(0.90$ [0.10, 2.07], $\mathrm{P}=0.779)$, the absolute $\mathrm{Ct}$ values for PTH receptor mRNA expression were high (33.1 and 32.9 in the control and PTH-treated subjects, respectively), indicating that lin-/AP+ cells expressed low levels of the PTH receptor and thus may not be direct targets for PTH action. In addition, as evident above, RANKL mRNA levels exhibited wide variability. The median Ct for RANKL expression was also >30, and as shown in Supplemental Figure 1, the variability of the mRNA analysis increased as an exponential function of the $\mathrm{Ct}$, with the less abundant genes clearly showing greater variability. Nonetheless, we should note that of the 60 genes analyzed in this study, only 10 exhibited the type of variability seen with RANKL (defined as an SD > 3).

\section{Effects of PTH on markers of proliferation, apoptosis, osteoblast differentiation, and Wnt target genes}

We used GSEA (see Statistical Methods) to evaluate if pre-specified clusters of genes in selected pathways were altered as a group in bone marrow lin-/AP+ cells from the PTH as compared to the control subjects. Table 2 lists the genes evaluated in the clusters for proliferation, apoptosis, and osteoblast differentiation markers, as well as the respective GSEA P-values, none of which were significant. In addition, none of the individual genes in these pathways showed significant differences between the PTH and control subjects (data not shown).

We also assessed a panel of $17 \mathrm{Wnt}$ target genes in the two groups (Table 2), but the overall GSEA P-value for this cluster was not significant. However, VEGF-C mRNA levels were higher in cells from PTH-treated subjects $(1.57[0.72,1.91])$ as compared to controls $(1.00$ $[0.43,1.34], \mathrm{P}=0.046)$, and EphB4 levels were lower in the PTH $(0.73[0.57,1.08])$ as compared to the control subjects $(1.00[0.70,2.01], \mathrm{P}=0.043)$. SOST mRNA levels were not detectable in the lin-/AP+ cells.

\section{PTH inhibition of BMP target genes in lin-/AP+ cells}

In contrast to the lack of effects of PTH on proliferation, apoptosis, or differentiation markers, there was a significant effect of PTH on the panel of BMP target genes tested. 
Thus, 8/9 genes evaluated in this pathway were reduced by PTH to varying degrees, resulting in the overall GSEA P-value being highly significant $(\mathrm{P}=0.005$, Figure 2$)$. As shown in Figure 2, Areb6/Zeb1 and Tieg were both significantly lower in the PTH-treated as compared to the control subjects ( $\mathrm{P}=0.009$ and 0.025 , respectively), and Hes- 1 and Smad7 were reduced in the PTH-treated subjects with a borderline P-value (0.07). In addition, there was a trend $(\mathrm{P}=0.077)$ for lower BMP-2 mRNA levels in cells from the PTH-treated $(0.77$ $[0.21,1.09])$ as compared to the control subjects $(1.00[0.53,1.63])$. mRNA levels for BMPs $1,4,5,6$, or 7 , or mRNA levels for BMP receptors IA or II did not differ between the two groups (data not shown).

\section{Effects of PTH on additional previously identified target genes}

We searched for additional PTH-regulated genes in lin-/AP+ cells in vivo in humans based on previous microarray studies using rat metaphyseal trabecular bone [5] and UMR osteoblastic cells [6]. Recognizing that the cell populations being isolated in our study versus the previous studies are clearly different, of 37 genes tested from the previous array studies $[5,6]$, we were able to identify similar, statistically significant changes in human lin $-/ \mathrm{AP}+$ cells to those described previously in c-fos (see earlier and Figure 3 ) and IFN $\gamma$, with borderline significant changes in IL-18 and latent TGF $\beta$ binding protein 1 (LTBP1, Figure $3)$.

\section{DISCUSSION}

Despite considerable efforts, the precise mechanisms or the target cells in the bone microenvironment through which intermittent PTH exerts an anabolic effect on bone remain unclear [4]. Moreover, there is little or no data on effects of PTH therapy on in vivo populations of osteoprogenitor or osteoblastic cells in humans. Further, because of the differences in bone metabolism between rodents and humans, findings in animal models must always be confirmed and extended with clinical studies. Thus, our study in postmenopausal women provides perhaps the first insight into the possible effects of intermittent PTH treatment on gene expression in vivo in human subjects.

Similar to the results described by Glover and colleagues [23], we found that even short term (14 days) PTH 1-34 treatment resulted in a robust increase in markers of bone formation. However, when compared to the study of Glover et al. [23], the greater increase in bone formation markers (P1NP and OCN) seen in our study after initiation of intermittent PTH 1-34 likely reflects our use of a $40 \mu \mathrm{g} /$ day dose as compared to the $20 \mu \mathrm{g} / \mathrm{day}$ dose used in their study. We chose the $40 \mu \mathrm{g} / \mathrm{day}$ (as opposed to the clinically approved $20 \mu \mathrm{g} /$ day) dose of PTH 1-34 since we wanted to maximize our chances of identifying possible gene expression changes over the relatively short 14 day duration of the study, and Neer et al. [1] found somewhat greater effects of the higher PTH 1-34 dose on BMD accrual. This higher dose may explain the fact that we observed significant increases in bone resorption markers over the relatively short 14 day treatment period; in contrast, changes in bone resorption markers may take longer to occur at the lower dose [23]. Nonetheless, we would stress that the $40 \mu \mathrm{g} /$ day dose is biologically relevant as an anabolic dose, based on the previously noted effects of this dose on BMD [1].

We used lin-/AP+ cells as a possible target cell population for several reasons. Previous work from our laboratory [8-10] as well as by Gronthos and colleagues [12] has shown that staining with AP markedly enriches for an osteoprogenitor population in human bone marrow. In fact, the latter study found that virtually all of the CFU-OBs from human marrow were contained within the AP+ fraction [12]. In addition, we have also previously demonstrated that estrogen deficiency is associated with increased RANKL protein expression by bone marrow $\mathrm{AP}+$ cells [8] and that serum bone resorption markers are 
correlated with RANKL expression by bone marrow lin-/AP+ cells [9]. Thus, bone marrow lin-/AP+ cells are certainly enriched for osteoprogenitor cells, although we acknowledge that there is likely heterogeneity in this selected population, which is not a pure osteoprogenitor cell population. We also recognize that this population in the marrow is likely different from the more mature osteoblasts found on bone surfaces; however, the latter cells are very difficult to access in humans (i.e., would require a bone biopsy, which is much more invasive than a bone marrow aspirate) and impossible to isolate from biopsy samples without prolonged in vitro culture following collagenase digestion, at which point the cells may no longer reflect changes that occurred during in vivo intermittent PTH exposure. Finally, given the relative small (42\%) increase in c-fos mRNA levels in the PTH-treated compared to the control group, as well as the low levels of expression of PTH receptor 1 in these cells, we acknowledge that the evidence that the lin-/AP+ cells isolated in this study are direct PTH targets is weak and indirect. Thus, the changes in gene expression we observed in these cells may be secondary to PTH action on other cell types not included in this population.

Somewhat surprisingly, PTH treatment had no measurable effect on markers of osteoblast differentiation, apoptosis, or proliferation in these cells. There are several potential explanations for this finding. First, it is possible that PTH affected one or more of these pathways earlier than we sampled our subjects (14 days), and we cannot exclude this possibility. Alternatively, it is possible that the major anabolic effect of PTH in vivo in humans is mediated by increasing the activity of mature osteoblasts and/or bone lining cells [25], as well as by increasing osteoblast lifespan via a decrease in apoptosis of mature osteoblasts [26]. These more mature cells are likely not included in the bone marrow lin-/ $\mathrm{AP}+$ population we obtained, and this may explain our failure to identify changes in osteoblast proliferation, differentiation, or apoptosis pathways.

We did, however, observe a significant increase in the expression of VEGF-C mRNA by lin $-/ \mathrm{AP}+$ cells from PTH-treated women. This finding is of particular interest given the recent demonstration by Jilka et al. [27] that PTH treatment of mice increased the number of blood vessels in the bone marrow cavity, as well as data from Langer et al. [28] showing that rats given daily injections of PTH exhibit increased blood vessels near sites of bone formation. Moreover, an increase in capillaries has also been noted in bone biopsies from patients with primary hyperparathyroidism [29]. Collectively, these previous findings, combined with our in vivo demonstration of increased VEGF-C mRNA levels in bone marrow lin-/AP+ following PTH treatment, indicate the need for further studies to define both the role both of angiogenesis, and of VEGF-C in particular, in mediating the anabolic skeletal response to PTH.

In addition, lin-/AP+ cells from PTH-treated women expressed somewhat lower levels of the EphB4 mRNA as compared to cells form the control women. While the biological significance of this finding remains to be better defined, decreased EphB4 expression on osteoblast precursors would be expected to reduce ephrinB2 signaling in osteoclast precursors and thereby increase osteoclastogenesis [30]. Thus, decreases in EphB4 expression in lin-/AP+ cells may augment the effects of the increased RANKL/OPG ratio we observed on osteoclastogenesis and bone resorption.

Intriguingly, we did find that PTH treatment led to a decrease in BMP target gene expression in lin-/AP+ cells in vivo, which was highly significant using the cluster GSEA analysis. While PTH, at least when given intermittently, has an anabolic effect on bone, there are several previous in vitro studies that are consistent with our observation of inhibition of BMP actions by PTH. Thus, using rat calvarial cells, Bellows et al. [31] found that PTH suppressed the differentiation of osteoprogenitor cells into functional osteoblasts. 
Subsequently, van der Horst et al. [32] treated murine bone marrow stromal cells and the mesenchymal progenitor cell line KS483 with either intermittent or continuous PTH and showed that both treatments inhibited differentiation of bone marrow stromal and KS483 cells. Moreover, in KS483 cells, PTH dose-dependently inhibited BMP-4 and -6-induced increases in AP activity, numbers of nodules, and the amount of mineral deposition [32]. Thus, there is clearly precedence, at least in vitro, for PTH to inhibit BMP effects on osteoprogenitor cells. While these earlier in vitro findings and our current in vivo data on PTH inhibition of BMP effects do not provide insights into the mechanism(s) for the anabolic effects of PTH on bone, they do suggest the hypothesis that suppression of BMP action in osteoblast progenitor cells by PTH could contribute to the waning of the anabolic response to PTH treatment that has been shown to occur in humans over time [33, 34]. In addition, this mechanism could also contribute to the attenuated response to retreatment with PTH 1-34 described by Finkelstein and colleagues [35], although this was not observed in a subsequent study by Cosman et al. [36]. Specifically, the inhibition of BMP actions by PTH may, over time, lead to a decrease in the bone marrow osteoblast progenitor cell pool. However, the waning of the anabolic effect of PTH, at least as defined by bone turnover markers, does not occur until 12-18 months following the initiation of PTH therapy [34, 37], whereas we observed a decrease in BMP target genes over 14 days of therapy. Since the decreases in BMP target genes we observed were relatively modest, it is possible that there is a longer term, cumulative effect of inhibition of BMP signaling on the marrow osteoprogenitor pool that contributes to the waning of the PTH effect on bone, although further studies are clearly needed to address this issue. However, while consistent with previous in vitro studies [32], we recognize that the inhibition of BMP target genes by PTH in lin-/AP+ cells we observed in vivo was relatively small, and further studies in mice and in humans are needed to validate these findings.

Using samples from these subjects and from the larger group of subjects involved in this study, we recently demonstrated that intermittent PTH treatment did lead to a significant reduction in peripheral blood and bone marrow sclerostin levels [13]. These findings, coupled with extensive data in mice that PTH suppresses sclerostin production [38-40], suggest that a major action of PTH in humans may be through regulating sclerostin production by osteocytes, leading to induction of Wnt activation within mature osteoblasts, but not in the progenitor cells we isolated as bone marrow lin-/AP+ cells. Of note, we were unable to detect expression of the SOST mRNA in these progenitor cells.

Our study has a number of strengths. To our knowledge, this work represents one of the first attempts in humans to analyze gene expression changes in a bone marrow population enriched for osteoprogenitor cells [8-10, 12] as compared to using either whole bone biopsies (which contain a mixture of cells) [41] or circulating peripheral blood monocytes [42]. In addition, we attempted to do so without in vitro culture of the cells, which could substantially alter their gene expression and other characteristics. We do, however, recognize several limitations of our work. First, while the lin-/AP+ cells are enriched for osteoprogenitor cells $[8-10,12]$, they likely are still a heterogenous population, including the expression of CD45 in a small proportion of the cells $(12.5 \%)$ [10]. Second, the changes in gene expression we observed were overall relatively small, on the order of $20-80 \%$. We should note, however, that it is unclear what the expected changes in gene expression might be in specific cells obtained from humans given a relatively modest stimulus (i.e., treatment with PTH), as compared to changes found in cell culture, in knock out mice with complete deletion of a gene, or rodents given relatively high doses of PTH. For example, changes of $20-80 \%$ in bone turnover markers in humans clearly have physiologically relevant consequences - this was, in fact the range of changes seen with the bone turnover markers following PTH treatment in the present study. In part due to this issue, similar studies in humans likely need at least 20 subjects per group, as opposed to the much smaller numbers 
that can be used in cell culture or mouse studies. Nonetheless, it is also possible that if we had a more highly purified osteoprogenitor population, the magnitude of changes we observed in gene expression would have been larger. Along these lines, our laboratory is currently attempting to further refine our isolation techniques. Third, we recognize that rather than obtaining samples in the control and PTH-treated subjects at the end of the study, it would have been preferable to obtain paired bone marrow aspirates from individual subjects both prior to and following either no treatment or PTH treatment. Our experience, however, has been that asking subjects to undergo two bone marrow aspirations as opposed to a single aspiration significantly reduces their willingness to participate in the study.

In summary, our findings identify several future directions for studying mechanisms of PTH action in humans. First, given the increasing evidence that PTH induces angiogenesis [2729], the role of increased VEGF-C production by bone marrow osteoprogenitor cells in mediating this effect and the anabolic response to PTH warrants further study. Second, while the inhibition of BMP target gene expression by PTH we observed in vivo does not explain the anabolic effects of PTH on bone and requires further validation, this finding does raise the possibility that PTH-induced inhibition of BMP actions may, over time, limit the availability of mature osteoblasts on bone surfaces and thereby contribute to the observed waning of the anabolic response to PTH.

\section{Research Highlights}

- We assessed the effects of intermittent PTH treatment on osteoprogenitor cells in vivo in humans.

- PTH led to a significant increase in mRNA levels of c-fos and VEGF-C.

- PTH also reduced the expression of BMP target genes, which may contribute to the waning of the anabolic response to PTH.

\section{Supplementary Material}

Refer to Web version on PubMed Central for supplementary material.

\section{Acknowledgments}

We would like to thank Kelley Hoey for help with sample preparation and Drs. Cheryl Ackert-Bicknell and Clifford Rosen for help in establishing the QPCR assays in our laboratory. We would also like to thank Elizabeth Atkinson, M.S. (Biostastistics) for help with the GSEA analyses.

Funding: This work was supported by NIH grants P01-AG004875 and UL1-RR24150 (Center for Translational Science Activities)

\section{REFERENCES}

1. Neer RM, Arnaud CD, Zanchetta JR, Prince R, Gaich GA, Reginster JY, Hodsman AB, Eriksen EF, Ish-Shalom S, Genant HK, Wang O, Mitlak BH. Effect of parathyroid hormone (1-34) on fractures and bone mineral density in postmenopausal women with osteoporosis. N Engl J Med. 2001; 344:1434-1441. [PubMed: 11346808]

2. Dempster DW, Cosman F, Kurland ES, Zhou H, Nieves J, Woelfert L, Shane E, Plavetic K, Muller R, Bilezikian J, Lindsay R. Effects of daily treatment with parathyroid hormone on bone microarchitecture and turnover in patients with osteoporosis: a paired biopsy study. J Bone Miner Res. 2001; 16:1846-1853. [PubMed: 11585349]

3. Lindsay R, Zhou H, Cosman F, Nieves J, Dempster DW, Hodsman AB. Effects if a one-month treatment with PTH(1-34) on bone formation on cancellous, endocortical, and periosteal surfaces of the human ilium. J Bone Miner Res. 2007; 22:495-502. [PubMed: 17227219] 
4. Khosla S, Westendorf JJ, Oursler MJ. Building bone to reverse osteoporosis and repair fractures. J Clin Invest. 2008; 118:421-428. [PubMed: 18246192]

5. Li X, Liu H, Qin L, Tamasi J, Bergenstock M, Shapses S, Feyen JHM, Notterman DA, Partridge NC. Determination of dual effects of parathyroid hormone on skeletal gene expression in vivo by mircoarray and network analysis. J Biol Chem. 2007; 282:33086-33097. [PubMed: 17690103]

6. Qin L, Qiu P, Wang L, Li X, Swarthout JT, Soteropoulos P, Tolias P, Partridge NC. Gene expression profiles and transcription factors involved in parathyroid hormone signaling in osteoblasts revealed by microarray and bioinformatics. J Biol Chem. 2003; 278:19723-19731. [PubMed: 12644456]

7. Locklin RM, Khosla S, Turner RT, Riggs BL. Mediators of the biphasic responses of bone to intermittent and continuously administered parathyroid hormone. J Cell Biochem. 2003; 89:180190. [PubMed: 12682918]

8. Eghbali-Fatourechi G, Khosla S, Sanyal A, Boyle WJ, Lacey DL, Riggs BL. Role of RANK ligand in mediating increased bone resorption in early postmenopausal women. J Clin Invest. 2003; 111:1221-1230. [PubMed: 12697741]

9. Sanyal A, Hoey KA, Modder UI, Lamsam JL, McCready LK, Peterson JM, Achenbach SJ, Oursler MJ, Khosla S. Regulation of bone turnover by sex steroids in men. J Bone Miner Res. 2008; 23:705-714. [PubMed: 18086006]

10. Undale A, Srinivasan B, Drake M, McCready L, Atkinson E, Peterson J, Riggs BL, Amin S, Moedder UI, Khosla S. Circulating osteogenic cells: characterization and relationship to rates of bone loss in postmenopausal women. Bone. 2010; 47:83-92. [PubMed: 20362080]

11. Chamberlain G, Fox J, Ashton B, Middleton J. Concise review: mesenchymal stem cells: their phenotype, differentiation capacity, immunological features, and potential for homing. Stem Cells. 2007; 25:2739-2749. [PubMed: 17656645]

12. Gronthos S, Fitter S, Diamond P, Simmons PJ, Itescu S, Zannettino ACW. A novel monoclonal antibody (STRO-3) identifies an isoform of tissue nonspecific alkaline phosphatase expressed by multipotent bone marrow stromal stem cells. Stem Cells Dev. 2007; 16:953-963. [PubMed: 18158854]

13. Drake MT, Srinivasan B, Modder UI, Peterson JM, McCready LK, Riggs BL, Dwyer D, Stolina M, Kostenuik P, Khosla S. Effects of parathyroid hormone treatment on ciculating sclerostin levels in postmenopausal women. J Clin Endocrinol Metab. 2010; 95:5056-5062. [PubMed: 20631014]

14. Kramer I, Loots GG, Studer A, Keller H, Kneissel M. Parathyroid hormone (PTH)-induced bone gain is blunted in SOST overexpressing and deficient mice. J Bone Miner Res. 2010; 25:178-189. [PubMed: 19594304]

15. Dafforn A, Chen P, Deng G, Herrler M, Iglehart D, Koritala S, Lato S, Pillarsietty S, Purohit R, Wang M, Wang S, Kurn N. Linear mRNA amplification from as little as 5ng total RNA for global gene expression. Biotechniques. 2004; 37:854-857. [PubMed: 15560142]

16. Nygaard V, Hovig E. Options available for profiling small samples: a review of sample amplification technology when combined with microarray profiling. Nucleic Acids Res. 2006; 34:996-1014. [PubMed: 16473852]

17. Radonic A, Thulke S, Mackay IM, Landt O, Siegert W, Nitsche A. Guideline to reference gene selection for quantitative real-time PCR. Biochem Biophys Res Commun. 2004; 313:856-862. [PubMed: 14706621]

18. Vandesompele J, De Preter K, Pattyn F, Poppe B, Van Roy N, De Paepe A, Speleman F. Accurate normalization of real-time quantitative RT-PCR data by geometeric averaging of multiple internal control genes. Genome Biol. 2002; 3 research0034.1-0-34.11.

19. Zhao S, Fernald RD. Comprehensive algorithm for quantitative real-time polymerase chain reaction. J Comput Biol. 2005; 12:1047-1064. [PubMed: 16241897]

20. Subramanian A, Tamayo P, Mootha VK, Mukherjee S, Ebert BL, Gillette MA, Paulovich A, Pomeroy SL, Golub TR, Lander ES, Mesirov JP. Gene set enrichment analysis: a knowledgebased approach for interpreting genome-wide experssion profiles. Proc Natl Acad Sci USA. 2005; 102:15545-15550. [PubMed: 16199517]

21. Efron B, Tibshirani R. On testing the significance of sets of genes. Ann Appl Statist. 2007; 1:107129. 
22. Huang JC, Sakata T, Pfleger LL, Bencsik M, Halloran BP, Bikle DD, Nissenson RA. PTH differentially regulates expression of RANKL and OPG. J Bone Miner Res. 2004; 19:235-244. [PubMed: 14969393]

23. Glover SJ, Eastell R, McCloskey EV, Rogers A, Garnero P, Lowery J, Belleli R, Wright TM, John MR. Rapid and robust response of biochemical markers of bone formation to teriparatide therapy. Bone. 2009; 45:1053-1058. [PubMed: 19679211]

24. Lee SK, Lorenzo JA. Parathyroid hormone stimulates TRANCE and inhibits osteoprotegerin messenger ribonuclei acid expression in murine bone marrow cultures: correlation with osteoclastlike cell formation. Endocrinol. 1999; 140(8):3552-3561.

25. Dobnig H, Turner RT. Evidence that intermittent treatment with parathyroid hormone increases bone formation in adult rats by activation of bone lining cells. Endocrinology. 1995; 136:36323638. [PubMed: 7628403]

26. Jilka RL. Molecular and cellular mechanisms of the anabolic effect of intermittent PTH. Bone. 2007; 40:1434-1446. [PubMed: 17517365]

27. Jilka RL, O' Brien CA, Bartell SM, Weinstein RS, Manolagas SC. Continuous elevation of PTH increases the number of osteoblasts via both osteoclast-dependent and - independent mechanisms. J Bone Miner Res. 2010; 25:2427-2437. [PubMed: 20533302]

28. Langer M, Prisby R, Peter Z, Boistel R, Lafage-Proust MH, Peyrin F. Quantitative investigation of bone microvascularization from 3D synchrotron micro-computed tomography in a rat model. Conf Proc IEEE Eng Med Biol Soc. 2009; 2009:1004-1007. [PubMed: 19964493]

29. Burkhardt, R.; Bartl, R.; Frisch, B.; Jager, K.; Mahl, C.; Hill, W.; Kettner, G. The structural relationship of bone forming and endothelial cells of the bone marrow. In: Arlet, J.; Ficat, RP.; Hungerford, DS., editors. Bone Circulation. Baltimore: Williams and Wilkins; 1984. p. 2-14.

30. Zhao C, Irie N, Takada Y, Shimoda K, Miyamoto T, Nishiwaki T, Suda T, Matsuo K. Bidirectional ephrinB2-EphB4 signaling controls bone homeostasis. Cell Metab. 2006; 4:111-121. [PubMed: 16890539]

31. Bellows CG, Ishida H, Aubin JE, Heersche JNM. Parathyroid hormone reversibly suppresses the differentiation of osteoprogenitor cells into functional osteoblasts. Endocrinology. 1990; 127:3111-3116. [PubMed: 2174346]

32. van der Horst G, Farih-Sips H, Lowik CWGM, Karperien M. Multiple mechanisms are involved in inhibition of osteoblast differentiation by PTHrP and PTH in KS483 cells. J Bone Miner Res. 2005; 20:2233-2244. [PubMed: 16294276]

33. Lindsay R, Nieves J, Formica C, Henneman E, Woelfert L, Shen V, Dempster D. Randomised controlled study of effect of parathyroid hormone on vertebral-bone mass and fracture incidence among postmenopausal women on oestrogen with osteoporosis. Lancet. 1997; 350:550-555. [PubMed: 9284777]

34. Finkelstein JS, Leder BZ, Burnett SAM, Wyland JJ, Lee H, Victoria de la Paz A, Gibson KJ, Neer RM. Effects of teriparatide, alendronate, or both on bone turnover in osteoporotic men. J Clin Endocrinol Metab. 2006; 91:2882-2887. [PubMed: 16684825]

35. Finkelstein JS, Wyland JJ, Leder BZ, Burnett-Bowie S-AM, Lee H, Juppner H, Neer RM. Effects of teriparatide retreatment in osteoporotic men and women. J Clin Endocrinol Metab. 2009; 94:2495-2501. [PubMed: 19401368]

36. Cosman F, Nieves JW, Zion M, Barbuto N, Lindsay R. Retreatment with teriparatide one year after the first teriparatide course in patients on continued long-term alendronate. J Bone Miner Res. 2009; 24:1110-1115. [PubMed: 19113926]

37. Cosman F, Wermers RA, Recknor C, Mauck KF, Xie L, Glass EV, Krege JH. Effects of teriparatide in postmenopausal women with osteoporosis on prior alendronate or raloxifene: differences between stopping and continuing the antiresorptive agent. J Clin Endocrinol Metab. 2009; 94:3772-3780. [PubMed: 19584192]

38. Bellido T, Ali AA, Gubrij I, Plotkin LI, Fu Q, O'Brien CA, Manolagas SC, Jilka RL. Chronic elevation of parathyroid hormone in mice reduces expression of sclerostin by osteocytes: a novel mechanism for normonal control of osteoblastogenesis. Endocrinology. 2005; 146:4577-4583. [PubMed: 16081646] 
39. Keller H, Kneissel M. SOST is a target gene for PTH in bone. Bone. 2005; 37:148-158. [PubMed: 15946907]

40. Silvestrini G, Ballanti P, Leopizzi M, Sebastiani M, Berni S, Di Vito M, Bonucci E. Effects of intermittent parathyroid hormone (PTH) administration on SOST mRNA and protein in rat bone. J Mol Histol. 2007; 38:261-269. [PubMed: 17549589]

41. Reppe S, Stilgren LS, Olstad OK, Brixen K, Nissen-Meyer LS, Gautvik KM, Abrahamsen B. Gene expression profiles give insight into the molecular pathology of bone in primary hyperparathyroidism. Bone. 2006; 39:189-198. [PubMed: 16516570]

42. Lei S-F, Wu S, Li L-M, Deng F-Y, Xiao S-M, Jiang C, Chen Y, Jiang H, Yang F, Tan L-J, Sun X, Zhu X-Z, Liu M-Y, Liu Y-Z, Chen X-D, Deng H-W. An in vivo genome wide gene expression study of circulating monocytes suggested GBP1, STST1, and CXCL10 as novel risk genes for the differentiation of peak bone mass. Bone. 2009; 44:1010-1014. [PubMed: 19223260] 


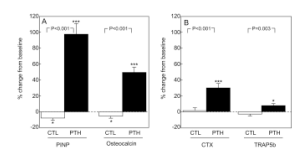

Figure 1.

Percent change from baseline in (A) bone formation markers (PINP, osteocalcin) and (B) bone resorption markers (CTX, TRAP5b) in the two groups of study subjects. Data are means and SEMs. ${ }^{*} \mathrm{P}<0.05 ;{ }^{* * *} \mathrm{P}<0.001$ versus baseline. $\mathrm{P}$-values for comparison of changes in each marker between groups are as indicated. 


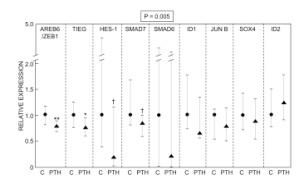

Figure 2.

Differences in BMP target genes in lin-/AP+ cells from control versus PTH treated subjects. Data are median and interquartile $\left(25^{\text {th }}-75^{\text {th }}\right.$ percentile) ranges. The numerical P-value is by the GSEA analysis, which provides a more robust means to analyze gene expression data and increases the power of detecting changes in genes occurring in pre-specified clusters, rather than in isolation (see Methods). ${ }^{* *} \mathrm{P}<0.01 ;{ }^{*} \mathrm{P}<0.05 ;{ }^{\dagger} \mathrm{P}=0.07$ versus control. 


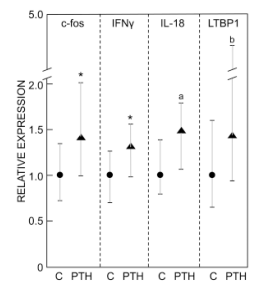

Figure 3.

Expression of c-fos, IFN $\gamma$, IL-18, and latent TGF $\beta$ binding protein 1 in lin-/AP+ cells from control versus PTH treated subjects. Data are median and interquartile $\left(25^{\text {th }}-75^{\text {th }}\right.$ percentile $)$ ranges. ${ }^{*} \mathrm{P}<0.05 ;{ }^{\mathrm{a}} \mathrm{P}=0.07 ;{ }^{\mathrm{b}} \mathrm{P}=0.08$ versus control. 
Table 1

Baseline anthropometric and biochemical variables in the study subjects. Data are means \pm SEM.

\begin{tabular}{|l|c|c|c|}
\hline & Control & PTH & P-value \\
\hline $\mathrm{N}$ & 19 & 20 & - \\
\hline Age, years & $66.4 \pm 1.7$ & $65.1 \pm 1.5$ & 0.577 \\
\hline Height, $\mathrm{m}$ & $1.63 \pm 0.01$ & $1.62 \pm 0.01$ & 0.513 \\
\hline Weight, kg & $74.9 \pm 2.0$ & $71.4 \pm 2.5$ & 0.296 \\
\hline Body mass index, kg/m ${ }^{2}$ & $28.2 \pm 0.8$ & $27.2 \pm 0.8$ & 0.374 \\
\hline Serum parameters & & & \\
\hline Calcium, mg/dl & $9.77 \pm 0.08$ & $9.67 \pm 0.07$ & 0.294 \\
\hline Phosphorus, $\mathrm{mg} / \mathrm{dl}$ & $3.81 \pm 0.08$ & $3.72 \pm 0.06$ & 0.364 \\
\hline Creatinine, $\mathrm{mg} / \mathrm{dl}$ & $0.81 \pm 0.03$ & $0.80 \pm 0.04$ & 0.832 \\
\hline 25-hydroxyvitamin D, ng/ml & $55.2 \pm 2.2$ & $60.2 \pm 2.9$ & 0.179 \\
\hline PINP, ug/L & $54.4 \pm 5.0$ & $54.9 \pm 4.2$ & 0.940 \\
\hline Osteocalcin, ng/mL & $24.2 \pm 1.6$ & $25.1 \pm 1.7$ & 0.694 \\
\hline CTx, ng/mL & $0.62 \pm .06$ & $0.65 \pm 0.06$ & 0.689 \\
\hline TRAP 5b, U/L & $4.37 \pm 0.30$ & $4.18 \pm 0.31$ & 0.668 \\
\hline
\end{tabular}


Table 2

Proliferation, apoptosis, and osteoblast differentiation marker genes evaluated in lin-/AP+ cells from control and PTH treated subjects. Shown also are the GSEA P-values for assessment of each of these panels of genes as a cluster in the PTH versus the control groups.

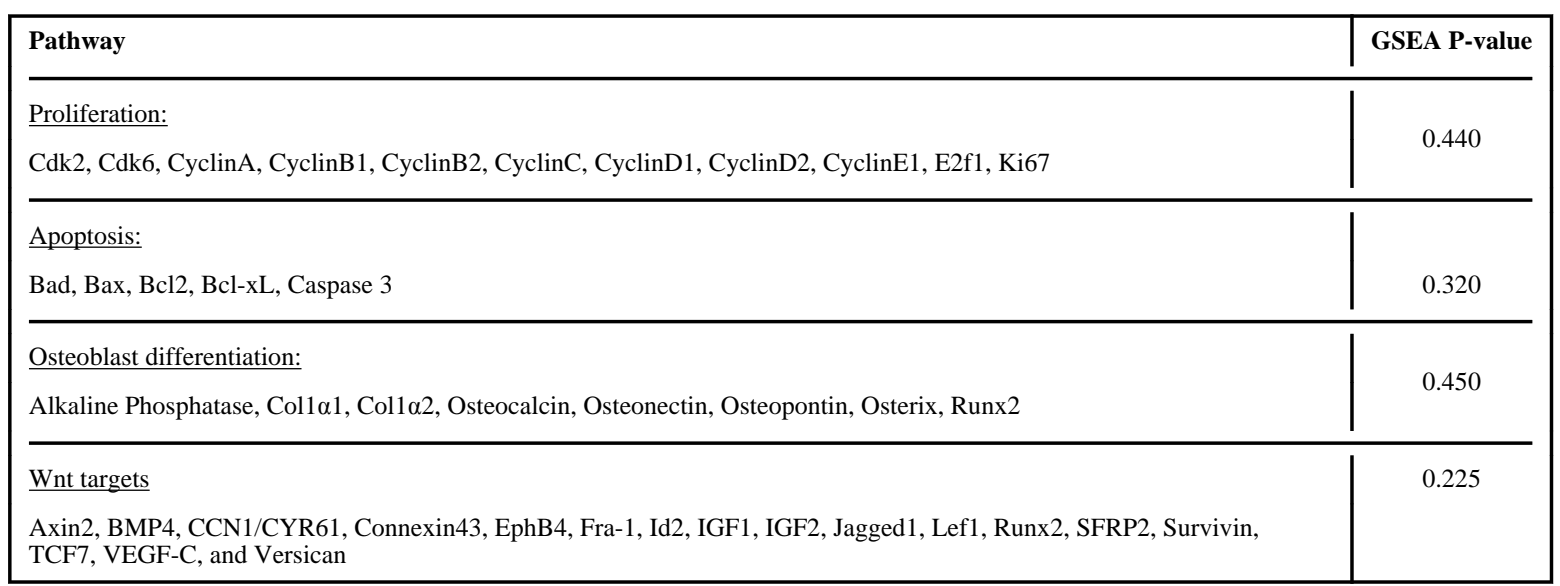

